\title{
Short-term results of a randomized clinical trial comparing Lichtenstein open repair with totally extraperitoneal laparoscopic inguinal hernia repair
}

\author{
A. Eklund ${ }^{1}$, C. Rudberg ${ }^{1}$, S. Smedberg ${ }^{2}$, L. K. Enander ${ }^{3}$, C. E. Leijonmarck ${ }^{4}$, J. Österberg ${ }^{5}$ and $^{6}$ \\ A. Montgomery ${ }^{6}$ \\ Departments of Surgery, ${ }^{1}$ Central Hospital, Västerås, ${ }^{2}$ Helsingborg Hospital, Helsingborg, ${ }^{3}$ Central Hospital, Karlstad, ${ }^{4}$ St Görans Hospital, Stockholm, \\ ${ }^{5}$ Uppsala University Hospital, Uppsala, ${ }^{6}$ Malmö University Hospital, Malmö, Sweden \\ Correspondence to: Dr A. Eklund, Department of Surgery, Central Hospital, 72189 Västerås, Sweden (e-mail: arne.eklund@ltv.se)
}

\begin{abstract}
Background: Laparoscopic herniorrhaphy has emerged as a recognized operative method for inguinal hernia repair. This study compared the short-term results of two tension-free methods of repair: totally extraperitoneal (TEP) laparoscopic patch repair and the open Lichtenstein mesh technique.

Methods: A total of 1513 men from 11 hospitals who presented with a primary unilateral inguinal hernia were randomized to one of the two methods. Operating time, short-term complications, reoperations, postoperative pain, consumption of analgesics, sick leave and time to resumption of normal physical activities were recorded.

Results: Some 1371 of the 1513 men underwent surgery, 665 in the TEP group and 706 in the Lichtenstein group. The median duration of operation was $55 \mathrm{~min}$ for both procedures and 91.0 per cent of the patients in both groups were discharged on the day of operation. Patients in the TEP group experienced less postoperative pain $(P<0.001)$, consumed fewer analgesics $(P<0.001)$, had a shorter period of sick leave ( 7 versus 12 days; $P<0.001$ ) and a shorter time to resumption of normal physical activity (20 versus 31 days; $P<0.001)$.

Conclusion: The TEP technique took no longer to perform, and was associated with less postoperative pain, a shorter period of sick leave and a faster recovery, compared with open Lichtenstein hernia repair.
\end{abstract}

Paper accepted 28 June 2006

Published online 24 July 2006 in Wiley InterScience (www.bjs.co.uk). DOI: 10.1002/bjs.5405

\section{Introduction}

The Lichtenstein hernia repair (open, tension-free mesh technique) is a simple and safe method for treatment of inguinal hernia. The recurrence rate is low, both in the hands of experts and for the average surgeon ${ }^{1-3}$. There has been a gradual increase in the number of Lichtenstein repairs performed in Sweden, with a corresponding decrease in the number of conventional sutured repairs ${ }^{4}$.

Simultaneously, early reports from non-randomized studies of laparoscopic hernia repair techniques showed a possible advantage of the totally extraperitoneal (TEP) patch technique over the transabdominal preperitoneal (TAPP) patch technique, with lower recurrence rates

The Editors have satisfied themselves that all authors have contributed significantly to this publication and fewer operative complications because the abdominal cavity is not entered ${ }^{5-7}$.

In 1993 the Swedish Multicentre trial of Inguinal hernia repair by Laparoscopy (SMIL) study group was formed to evaluate the possible benefits of laparoscopic hernia repair compared with open techniques. Early results from the SMIL-1 trial, a randomized study comparing the TAPP technique with Shouldice repair, showed benefits for the laparoscopic operation in terms of less postoperative pain, shorter sick leave and shorter time to return to normal physical activities ${ }^{8}$.

Encouraged by these results it was decided to undertake a study comparing an open tension-free mesh technique (Lichtenstein) with a laparoscopic mesh repair (TEP). This study was designed to compare the recurrence rate at 5 years as the primary endpoint. Secondary endpoints 
were operative complications, postoperative recovery and complaints at 5 years. This article presents the short-term results up to 3 months after surgery.

\section{Patients and methods}

Eleven hospitals participated: two university, six regional and three county hospitals. The study was approved by the local ethics committees.

\section{Patients}

Patients eligible for inclusion were men aged $30-70$ years referred to hospital with an inguinal hernia. Exclusion criteria were recurrent hernia, scrotal or bilateral hernia, and previous lower abdominal surgery, such as Pfannenstiel, lower midline and other abdominal incisions below the umbilicus on the side of the hernia. Patients who were considered unable to participate in the postoperative follow-up owing to drug misuse, psychiatric disorders and language difficulties were also excluded. A high operative risk (American Society of Anesthesiologists (ASA) fitness grade more than III) or bleeding diathesis were considered contraindications from an anaesthetic point of view. All operations were planned as day cases. Instructions were given to all patients to resume normal daily activities and return to work as soon as possible, irrespective of the operative method. After giving informed consent, patients were randomized in blocks of 20, which were computergenerated and stratified for each centre, using numbered envelopes. The study was planned in accordance with the intention-to-treat principle.

\section{Surgical procedures}

The TEP technique used a three-port system: one 10-mm port close to the umbilicus for the $30^{\circ}$ angled videoscope and two 5-mm working ports in the lower midline. A balloon dissector $\left(\mathrm{PBD}^{\circledR}\right.$ 100; Origin Medsystem, Menlo Park, California, USA) was used to create a preperitoneal working space. The peritoneal space was dissected further using forceps and scissors to expose the inguinal region. Downward and medial dissection was extended several centimetres below the pubic bone and Cooper's ligament, exposing the spermatic vessels and the vas deferens. The extent of the lateral dissection was as far as the anterior-superior iliac spine. The hernia sac was generally invaginated into the preperitoneal space. In some patients with a large hernia the sac was transected. In these patients the peritoneum was closed to prevent the intestine from coming into contact with the mesh. A polypropylene mesh (Atrium Medical, Hudson, New Hampshire, USA) measuring 12 by $15 \mathrm{~cm}$ was placed to cover the hernial orifice and the inside of Hesselbach's triangle. The mesh was fixed with staples (Origin-Tacker ${ }^{\circledR} 5 \mathrm{~mm}$; Origin Medsystem) to Cooper's ligament and the abdominal wall above the iliopubic tract. Some $20 \mathrm{ml} 0.5$ per cent bupivacaine was usually instilled into the preperitoneal space before evacuation of the gas.

The open procedure was performed according to the Lichtenstein technique ${ }^{1}$. The cremaster muscle together with external spermatic vessels and the genital branch of the genitofemoral nerve were divided at the internal ring. Indirect as well as direct hernia sacs were invaginated or resected. Before repair, the femoral canal was examined digitally for the presence of a possible femoral hernia. A dilated internal ring or a bulging posterior wall of the inguinal canal was reconstructed to facilitate placement of the mesh. Space was made by blunt dissection under the external aponeurosis in medial, cranial and lateral directions. A polypropylene mesh (Atrium Medical) measuring 7.5 by $12-15 \mathrm{~cm}$ was anchored with a running 2/0 polypropylene suture overlapping the pubic tubercle and then extending along the inguinal ligament inferiorly. Interrupted sutures were placed medially and superiorly. A slit was made laterally in the mesh to permit passage of the spermatic cord and the ilioinguinal nerve. Lateral to the cord the slit was closed by a suture through the lower rims of the two tails and the inguinal ligament. At the end of the operation the wound was infiltrated with $20 \mathrm{ml} 0.5$ per cent bupivacaine. In the open group a single prophylactic dose of cefuroxime was used. For patients with an allergy to penicillin or cephalosporins, clindamycin was employed instead.

\section{Surgeons}

Forty-eight board-certified surgeons participated in the trial, 22 in the laparoscopic group and 26 in the open group. The laparoscopic surgeons were experienced in laparoscopic surgery (cholecystectomy, appendicectomy, fundoplication) and had performed at least 25 TEP operations before entering the study. The open surgeons were experienced with the Lichtenstein technique. No surgeon did both techniques.

\section{Data collection and follow-up}

Demographic data, predisposing factors and functional status were recorded before operation. Functional status was assessed by three tests: climbing stairs, squatting and rising from a bed. Unrestricted activity was graded as 1, 
some restriction as 2 , and great difficulty as 3 points. The tests were recorded by an independent observer (nurse) and combined into a functional index score (range 3-9 points), as used in a previous study ${ }^{8}$. The type of anaesthesia, duration of operation (skin to skin), type of hernia according to the Nyhus classification ${ }^{27}$, operative complications, length of hospital stay and complications at discharge were recorded. Using a visual analogue scale (VAS; $0-100 \mathrm{~mm}$ ) the patients recorded pain once daily during the first week after operation, and once a week thereafter for the next 11 weeks. Patients were asked to report their daily intake of oral analgesics during the first week after surgery. A combined drug, paracetamol $325 \mathrm{mg}$ with dextropropoxyphene $32.5 \mathrm{mg}$, was prescribed. The day of complete recovery from the operation, when normal physical activities could be performed without difficulty, was registered by the patient. An independent observer examined each patient 1 week after surgery, assessed the functional status and decided whether further sick leave was necessary. At the same visit and after 3 months an independent surgeon examined the patient for the presence of complications, complaints or recurrence.

\section{Statistical analysis}

The sample size was calculated such that a 5 percent difference $(\alpha=0.05)$ in recurrence rate at 5 years between the groups could be detected with a power of 0.9 . This required a sample size of 1200 patients. Continuous data were presented as mean(s.d.) and compared using Student's $t$ test (two tailed). Non-parametric data were presented as median (range) and compared using the Mann-Whitney $U$ test. Frequencies were compared by Pearson's $x^{2}$ test and Fisher's exact test. Data analysis was carried out with SPSS $^{\circledR}$ version 10.0 (SPSS, Chicago, Illinois, USA).

\section{Results}

Between November 1996 and August 2000 a total of 1513 men were randomized, 758 to the TEP group and 755 to the Lichtenstein group. For various reasons 142 patients (9.4 per cent) did not have surgery (Fig. 1). There were significantly more dropouts in the TEP group (93 versus 49; $P<0.001$ ). After exclusion of the dropouts, 665 patients remained in the TEP group and 706 in the Lichtenstein group. There were no significant differences between groups in demographic data or type of hernia according to the Nyhus classification (Table 1). Most operations were performed under general anaesthesia (TEP, 99.7 per cent; Lichtenstein, 70.4 per cent). The mean number of operations per surgeon was 30 (range 6-57) for the TEP group compared with 27 (range 1-61) in the Lichtenstein group. The median duration of operation was $55 \mathrm{~min}$ in both groups, with a range of 12-180 $\mathrm{min}$ in the TEP group and 20-145 min for the Lichtenstein technique. The duration of operation in the TEP group decreased continuously throughout the study with an increasing number of operations $(r=0.91)$. In both groups, 91.0 per cent of the patients were discharged on the day of surgery; all patients in the TEP group and

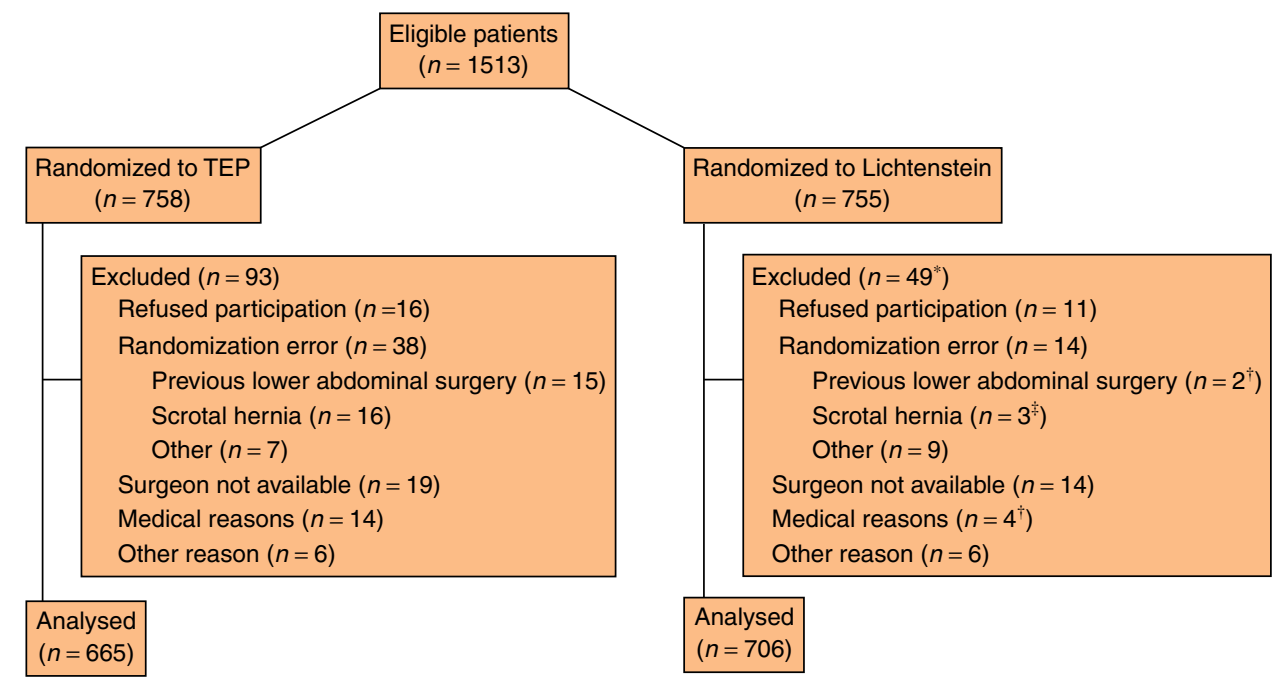

Fig. 1 CONSORT diagram describing randomized comparison of totally extraperitoneal (TEP) laparoscopic repair with the Lichtenstein open technique of inguinal hernia repair. ${ }^{*} P<0.001$ ( $\chi^{2}$ test), $\dagger P<0.002$ versus TEP (Fisher's exact test), $\ddagger P=0 \cdot 004$ versus TEP (Fisher's exact test) 
Table 1 Patient characteristics in 1371 men with a unilateral inguinal hernia

\begin{tabular}{|c|c|c|}
\hline & $\begin{array}{c}\text { TEP } \\
(n=665)\end{array}$ & $\begin{array}{l}\text { Lichtenstein } \\
\quad(n=706)\end{array}$ \\
\hline Age (years)* & $53(10)$ & $52(10)$ \\
\hline Weight $(\mathrm{kg})^{\star}$ & $80(10)$ & $81(10)$ \\
\hline Height $(\mathrm{cm})^{\star}$ & $179(6)$ & $179(7)$ \\
\hline Smoker & $130(19.5)$ & $129(18 \cdot 3)$ \\
\hline Chronic obstructive lung disease & $16(2 \cdot 4)$ & $13(1 \cdot 8)$ \\
\hline Steroid medication & $14(2 \cdot 1)$ & $12(1 \cdot 7)$ \\
\hline \multicolumn{3}{|l|}{ Size of hernia } \\
\hline Visible & $507(76 \cdot 2)$ & $513(72 \cdot 7)$ \\
\hline Palpable only & $156(23.5)$ & $187(26.5)$ \\
\hline Unknown & $2(0.3)$ & $6(0.8)$ \\
\hline \multicolumn{3}{|l|}{ ASA grade } \\
\hline 1 & $584(87.8)$ & $633(89.7)$ \\
\hline II & $66(9.9)$ & $57(8 \cdot 1)$ \\
\hline III & $5(0.8)$ & $5(0.7)$ \\
\hline Unknown & $10(1.5)$ & $11(1.6)$ \\
\hline \multicolumn{3}{|l|}{ Occupational exertion } \\
\hline Light & $206(31.0)$ & $233(33.0)$ \\
\hline Moderate & $163(24.5)$ & $160(22 \cdot 7)$ \\
\hline Heavy & $169(25.4)$ & $176(24.9)$ \\
\hline Retired & $102(15 \cdot 3)$ & $93(13.2)$ \\
\hline Unemployed & $21(3 \cdot 2)$ & $39(5.5)$ \\
\hline Unspecified occupation & $4(0.6)$ & $5(0.7)$ \\
\hline \multicolumn{3}{|l|}{ Nyhus classification } \\
\hline II & $213(32 \cdot 0)$ & $195(27 \cdot 6)$ \\
\hline IIla & $222(33.4)$ & $237(33.6)$ \\
\hline Illb & $223(33.5)$ & $262(37.1)$ \\
\hline IIIC & $2(0 \cdot 3)$ & $3(0.4)$ \\
\hline Unknown & $5(0.8)$ & $9(1 \cdot 3)$ \\
\hline
\end{tabular}

Values in parentheses are percentages unless indicated otherwise, *mean(s.d.). TEP, totally extraperitoneal; ASA, American Society of Anesthesiologists fitness score.

99.1 per cent in the Lichtenstein group were discharged home within $24 \mathrm{~h}$.

\section{Complications}

The overall operative and early postoperative complication rate was 12.2 per cent for TEP repair and 12.3 per cent for Lichtenstein repair (Table 2). There were two major operative complications in each group. In the TEP group one patient was anaesthetized with a laryngeal mask and developed airway obstruction after 50 min of surgery. Endotracheal intubation was not possible and the operation was converted to an open procedure under local anaesthesia. The other patient needed reoperation within $24 \mathrm{~h}$ after initial surgery because of mechanical small bowel obstruction. This was caused by accidental fixation of the small bowel to the peritoneum during suture repair of a peritoneal tear. In the Lichtenstein group one patient had an anaesthetic complication with a short period of cardiac arrest at the beginning of the operation. This was probably a side-effect
Table 2 Operative and early postoperative results after hernia repair

\begin{tabular}{lccr} 
& TEP & Lichtenstein & $P^{*}$ \\
\hline Operative complications & $32(4.8)$ & $15(2.1)$ & 0.006 \\
Minor & & & \\
$\quad$ Bleeding from epigastric vessels & $6(0.9)$ & $4(0.6)$ & 0.537 \\
Technical problem & $12(1.8)$ & $0(0)$ & $<0.001$ \\
Nerve injury & $0(0)$ & $9(1.3)$ & 0.004 \\
Conversion & $12(1.8)$ & $0(0)$ & $<0.001$ \\
Major & & & \\
Haemorrhage & $0(0)$ & $1(0.1)$ & 1.000 \\
Anaesthetic related & $1(0.2)$ & $1(0.1)$ & 1.000 \\
Reoperation within 24 h & $1(0.2)$ & $0(0)$ & 0.485 \\
Complications at discharge & $49(7.4)$ & $72(10.2)$ & 0.065 \\
Urinary retention & $28(4.2)$ & $53(7.5)$ & 0.010 \\
Haematoma & $10(1.5)$ & $10(1.4)$ & 0.893 \\
Anaesthesia related & $10(1.5)$ & $9(1.3)$ & 0.717 \\
Other & $1(0.2)$ & $0(0)$ & 0.485 \\
Complications at 1 week & $99(17.3)$ & $107(17.5)$ & 0.889 \\
Haematoma $\geq 50$ cm ${ }^{2}$ & $60(10.5)$ & $79(12.9)$ & 0.184 \\
Seroma & $5(0.9)$ & $5(0.8)$ & 1.000 \\
Superficial infection/cystitis & $8(1.4)$ & $4(0.7)$ & 0.206 \\
Urinary tract discomfort & $5(0.9)$ & $6(1.0)$ & 1.000 \\
Testicular discomfort & $7(1.2)$ & $4(0.7)$ & 0.313 \\
Pain & $9(1.6)$ & $8(1.3)$ & 0.713 \\
Reoperation & $1(0.2)$ & $1(0.2)$ & 1.000 \\
Other & $4(0.7)$ & $0(0)$ & 0.055 \\
& & & \\
& & &
\end{tabular}

Values in parentheses are percentages. TEP, totally extraperitoneal.

*Fisher's exact or $\chi^{2}$ test.

of the drug used for the spinal anaesthesia, lidocain. The operation was completed. The other patient had bleeding from the external iliac vein that was controlled by suturing.

In the TEP group the surgeons registered the problem of leakage of gas into the peritoneal cavity in 262 patients (39.4 per cent). In 109 (15.9 per cent) this was managed without any further intervention and in 111 patients (16.7 per cent) it was controlled using a Veress needle. In 31 patients ( 4.7 per cent) the peritoneal tear was closed, in seven patients ( 1.1 per cent) gas leakage led to conversion and in four patients $(0.6$ per cent) this information was missing. The incidence of gas leakage had a tendency to decrease with increasing surgical experience.

Altogether there were 12 TEP conversions (1.8 per cent), eight ( 1.2 per cent) to an open operation and four $(0.6$ per cent) to a TAPP procedure. The main reason for conversion from TEP to open operation was surgical difficulty (gas leakage, adhesions, bleeding and anatomical difficulties); in one patient anaesthetic problems led to conversion. Conversion from TEP to TAPP repair was because of gas leakage due to large peritoneal tears in three patients and bleeding in one.

Urinary retention was the most common complication at discharge in both groups and was more common in the 
Lichtenstein group $(P=0 \cdot 010)$. One patient in the TEP group had a nasal fracture after an accidental fall in the recovery room.

Some $86 \cdot 5$ per cent of the patients attended the 1 -week check-up (5-10 days after surgery). The complication rate at 1 week was 17.3 per cent after TEP and 17.5 per cent after Lichtenstein repair. During the first week there were two reoperations: one in the Lichtenstein group because of neuralgia of the genitofemoral nerve, and one in the TEP group because of gangrene of the caecum that had herniated through a hole in the peritoneum. The latter patient had undergone conversion from TEP to Lichtenstein repair because of problems with intraperitoneal gas leakage. 'Other' complications in the TEP group included postoperative haematomas in two patients $(0.3$ per cent), who were managed conservatively as inpatients for 5 and 7 days, stroke on the fifth day after surgery and thrombophlebitis in the right arm. There were no perioperative or postoperative deaths.

\section{Postoperative recovery}

Patients in the TEP group experienced less pain after operation than those in the Lichtenstein group at each time point. Pain, recorded as a cumulative median (range) VAS score registered during the first postoperative week (days 1 , $2,3,5$ and 7), was $105(0-440) \mathrm{mm}$ in the TEP group and 175 (0-440) $\mathrm{mm}$ in the Lichtenstein group (Fig. 2). Fewer analgesics were consumed in the TEP group (Fig. 3). At weeks 4, 6 and 8 there was a small but significant difference in pain in favour of the TEP group $(P=0.002)$. This difference remained at 12 weeks $(P=0 \cdot 011)$.

Before operation the median (range) combined functional index score was $3(3-9)$ in the TEP group and 3 $(3-7)$ in the Lichtenstein group. At 1 week the score was 3 (3-9) in both groups, but more patients in the Lichtenstein group than the TEP group had a score above $3(P<0.001)$ (Fig. 4).

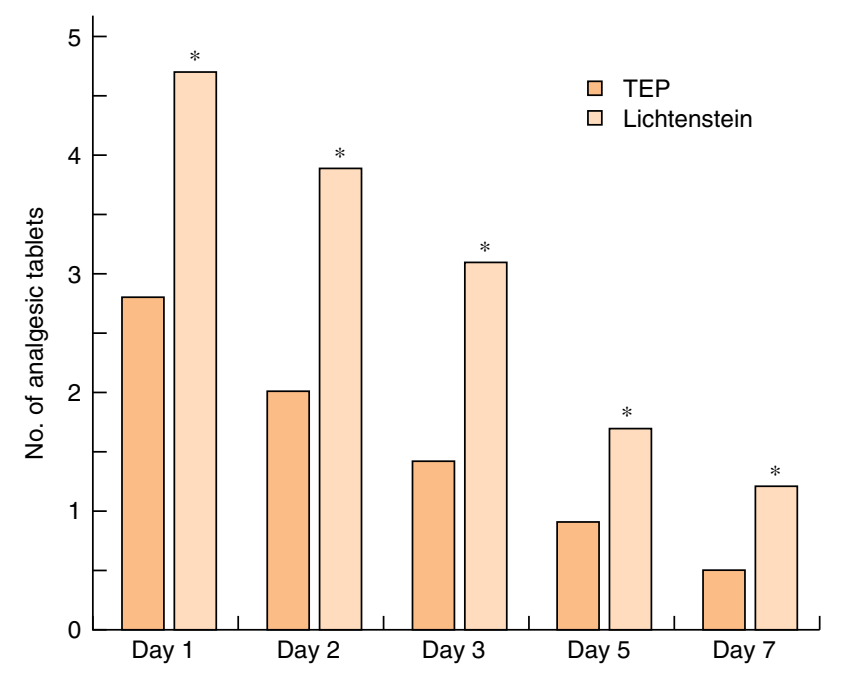

Fig. 3 Mean analgesic consumption after inguinal hernia repair. ${ }^{*} P<0.001$ versus totally extraperitoneal (TEP) repair (Mann-Whitney $U$ test)

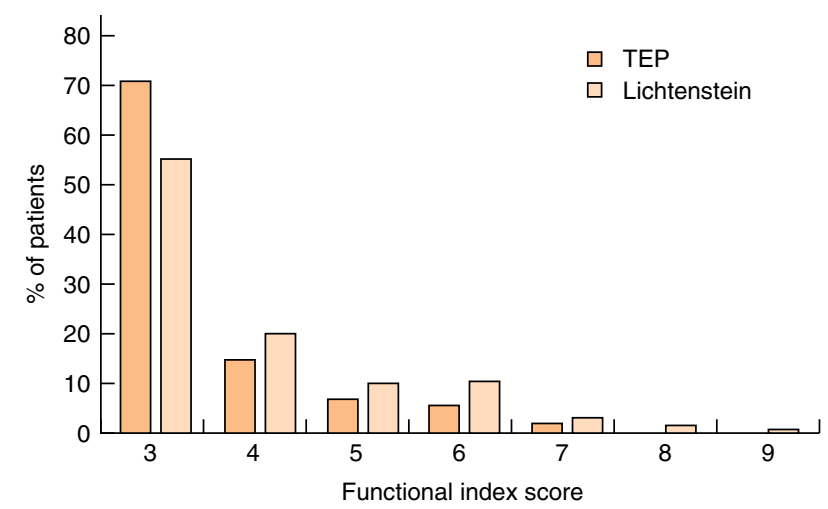

Fig. 4 Functional index scores 1 week after inguinal hernia repair. TEP, totally extraperitoneal hernia repair $\left(\chi^{2}\right.$ test $)$

Details regarding sick leave for 96.5 per cent of patients receiving working compensation were analysed. The

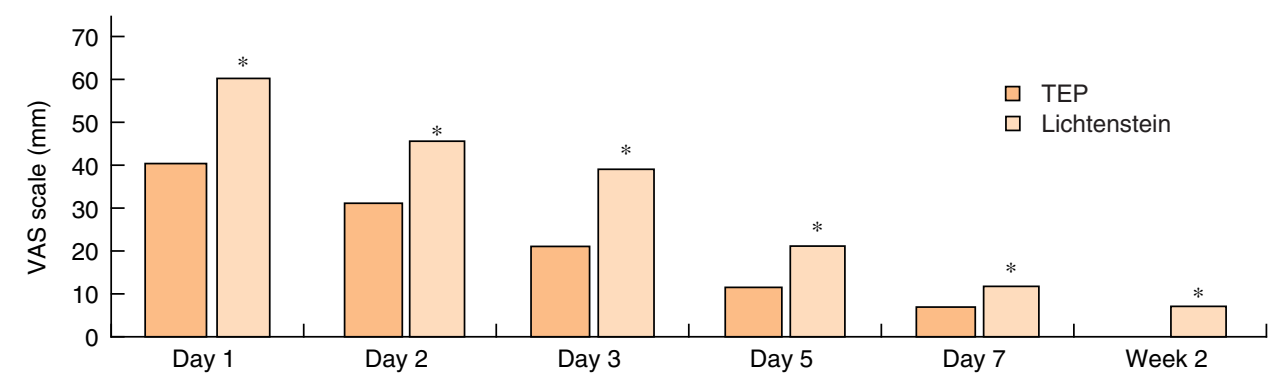

Fig. 2 Median pain scores measured on a visual analogue scale (VAS) after inguinal hernia repair. ${ }^{*} P<0.001$ versus totally extraperitoneal (TEP) repair (Mann-Whitney $U$ test) 
median (range) sick leave was $7(0-77)$ days in the TEP group and $12(0-55)$ days in the Lichtenstein group $(P<0.001)$. Subgroup analysis showed that there was a difference in sick leave for occupations involving light versus moderate and moderate versus heavy exertion for both groups $(P<0 \cdot 001)$. Irrespective of occupational exertion, sick leave was shorter in the TEP group (Table 3). The self-reported time to full recovery was a median (range) of $20(0-179)$ days in the TEP group and $31(0-163)$ days in the Lichtenstein group $(P<0.001)$.

\section{Follow-up at 3 months}

The 3-month follow-up appointment (2-5 months after surgery) was attended by 88.0 per cent of the patients. The complaint rate was 14.1 per cent in the TEP group and 16.3 per cent in the Lichtenstein group (Table 4). Five late infections were reported. One patient in the TEP group had a soft tissue abscess 4 weeks after surgery that required percutaneous drainage as an inpatient for 14 days. The mesh was not affected. The other four infections were in the Lichtenstein group, but these were superficial and only one patient required oral antibiotics. There were two reoperations, both in the TEP group. One patient had pain from a staple (the most superior and lateral staple), which was removed under local anaesthesia 20 days after the initial operation. The other patient underwent laparoscopic adhesiolysis 5 weeks after the initial procedure because of small bowel obstruction. This was caused by a short adhesion between the small bowel and the mesh. Five recurrences were reported at the 3-month followup, all in the TEP group ( 0.8 per cent). During the 3 months of follow-up there were 11 major complications (operative complications, reoperations and readmissions), eight (1.2 per cent) among 665 patients in the TEP group and three $(0.4$ per cent) among 706 in the open group $(P=0.030)$.

Table 3 Sick leave

\begin{tabular}{|c|c|c|c|}
\hline & \multicolumn{2}{|c|}{ Sick leave (days) } & \multirow[b]{2}{*}{$P^{*}$} \\
\hline & TEP & Lichtenstein & \\
\hline \multicolumn{4}{|c|}{ Occupational exertion } \\
\hline Light & $\begin{array}{c}4.5(0-77) \\
(n=192)\end{array}$ & $\begin{array}{l}7(0-37) \\
(n=228)\end{array}$ & $<0.001$ \\
\hline Moderate & $\begin{array}{c}8(0-39) \\
(n=159)\end{array}$ & $\begin{array}{l}13(0-55) \\
(n=151)\end{array}$ & $<0.001$ \\
\hline Heavy & $\begin{array}{l}12(0-62) \\
(n=166)\end{array}$ & $\begin{array}{l}17(0-54) \\
(n=171)\end{array}$ & $<0.001$ \\
\hline
\end{tabular}

Values are median (range). TEP, totally extraperitoneal.

*Mann-Whitney $U$ test.
Table 4 Complaints at 3 months after hernia repair

\begin{tabular}{|lccr|} 
& $\begin{array}{c}\text { TEP } \\
(n=589)\end{array}$ & $\begin{array}{c}\text { Lichtenstein } \\
(n=618)\end{array}$ & \multicolumn{1}{c|}{$P^{*}$} \\
\hline Pain or discomfort & $45(7.6)$ & $51(8.3)$ & 0.694 \\
Seroma & $4(0.7)$ & $1(0.2)$ & 0.207 \\
Numbness & $3(0.5)$ & $22(3.6)$ & $<0.001$ \\
Neuralgia & $3(0.5)$ & $8(1.3)$ & 0.151 \\
Scrotal discomfort & $16(2.7)$ & $6(1.0)$ & 0.023 \\
Orchitis & $0(0)$ & $2(0.3)$ & 0.500 \\
Sex-related complaints & $1(0.2)$ & $2(0.3)$ & 1.000 \\
Infection & $1(0.2)$ & $4(0.6)$ & 0.375 \\
Reoperation & $2(0.3)$ & $0(0)$ & 0.238 \\
Other & $8(1.4)$ & $5(0.8)$ & 0.356 \\
Total & $83(14.1)$ & $101(16.3)$ & 0.277 \\
\end{tabular}

Values in parentheses are percentages. TEP, totally extraperitoneal. *Fisher's exact or $\chi^{2}$ test.

\section{Discussion}

This randomized multicentre study compared the shortterm results of two well recognized tension-free mesh techniques for inguinal hernia repair: the laparoscopic TEP technique and the open Lichtenstein technique. The latter is regarded as the 'gold standard' for inguinal hernia repair in Sweden today'.

The major strength of this study was the large number of patients and the study design. The operative methods in the two groups were well defined and only patients with primary unilateral inguinal hernias were included. Other studies have mixed patients with primary and recurrent hernias, and various types of open repair. The argument for this is that it reflects everyday clinical work outside specialized centres ${ }^{10,11}$, but it leads to difficulties when interpreting the results.

One possible weakness with this study was the surgeons' relative inexperience with the TEP operation. The laparoscopic group also had more dropouts, and there were two main reasons for this. First, for laparoscopic procedures the surgeons were more concerned about previous lower abdominal surgery and whether the hernia extended into the scrotum. For the open procedure, these factors could more easily be overlooked. Second, the anaesthetists were more reluctant to administer general anaesthesia to patients with a high ASA grade for a planned laparoscopic operation. This merely reflects the limitations of laparoscopic hernia repair, but it does not bias the results of this comparison of TEP and Lichtenstein repair when it was possible to use the laparoscopic technique. A further problem was that the patients did not always use the prescribed analgesic drug after surgery; some used other regular analgesic agents. This practice was observed in both groups and so this 
finding was deemed to be an independent factor that did not influence the overall results.

The laparoscopic technique has been criticized because of the need for general anaesthesia. In this study, however, most patients in the Lichtenstein group also had general anaesthesia. The reason for this was tradition, patient preference and, very occasionally, anaesthetic considerations. According to the Swedish hernia register ${ }^{9}$ there has been a shift from regional to general anaesthesia during the past 10 years. In a survey from Scotland, where 95 per cent of the patients had open hernia repair, 85 per cent of these patients had general anaesthesia ${ }^{12}$.

Despite the use of general anaesthesia, the majority of patients in both groups were discharged from hospital on the day of surgery. Similar results with regard to discharge on the day of operation are found when using local anaesthesia for hernia repair ${ }^{13}$. Currently 70 per cent of all patients in Sweden, including those who have had emergency operations, are discharged on the day of surgery ${ }^{9}$.

The duration of operation was similar for both techniques, which is in accordance with other randomized studies ${ }^{14,15}$. The incidence of peritoneal tears and intra-abdominal gas leakage is reported to be 40-47 per cent ${ }^{16,17}$. This often complicates the TEP operation and can become a reason for conversion, which is reported in 5 per cent of procedures ${ }^{18}$. In this study intra-abdominal gas leakage was encountered relatively frequently and it is reasonable to assume that this was due to peritoneal tears. In spite of this the conversion rate was low. The use of a Veress needle to deflate the abdomen or the immediate repair of any peritoneal tear generally solved the problem.

The relatively high frequency of major complications in the TEP group is of concern. Postoperative haemorrhage has been reported in 0.4 per cent of 5203 TEP repairs ${ }^{19}$, which is in accordance with the present results. Intestinal complications are rare but well recognized during laparoscopic surgery ${ }^{19-21}$. To avoid this serious and potentially dangerous complication, the surgeon must search for peritoneal tears and try to close them, taking care to avoid damaging the bowel.

Postoperative recovery was significantly better in the TEP group. These findings are in accordance with other studies ${ }^{10,20,22}$. It is often stated that the duration of sick leave depends on tradition and the social insurance system, rather than the real need to be off work after surgery ${ }^{23}$. The present data show clearly that the degree of occupational exertion influenced the length of sick leave. This, together with the fact that the TEP group in general had a shorter period of sick leave, indicates that convalescence was directly related to the degree of surgical trauma.

The functional test indicates the patient's capacity for ordinary daily activities. In the present study the functional test after 1 week showed significantly less impairment in the laparoscopic group. Similar results were obtained by Berndsen et al. ${ }^{8}$, and also by Liem et al. ${ }^{24}$ who compared curled sit-up and straight leg raising at 1 and 6 weeks after surgery.

Very little has been reported regarding pain at 3 months after surgery. One survey of 5509 patients after inguinal hernia repair, using various open and laparoscopic techniques, showed severe or very severe pain in 3.6 per cent and mild or moderate pain in 43 per cent $t^{25}$. The overall rate of reported pain or discomfort (including neuralgia and scrotal discomfort) 3 months after surgery in the present study was just under 11 per cent in both groups. No patient reported severe pain and fewer patients than in the study by Courtney et al. ${ }^{25}$ had mild to moderate pain.

Recurrence at 3 months is considered a technical failure. In this study all five recurrences at 3 months occurred in the TEP group. It should be noted that one surgeon was responsible for four of these recurrences. This surgeon performed 25 operations in this study and three of the recurrences were among the first 12 operations undertaken. A similar finding was encountered in another large randomized trial, in which a single institution had a disproportionately high number of recurrences ${ }^{10}$. The learning curve for laparoscopic hernia repair is reported as being between 30 and 250 operations ${ }^{18,26}$. This is more than the 25 TEP repairs required before the surgeons could participate in the present study. Many of the surgeons in the laparoscopic group could still have been experiencing their learning curve. The findings of decreasing operating time and a tendency towards fewer patients with intra-abdominal gas as the study progressed support this conclusion. The fact that six of 22 surgeons in the TEP group were responsible for 83 per cent of the operative complications (conversions, reoperation, postoperative haemorrhage and recurrences) further supports this. Such a long learning curve might be considered to be a drawback of the laparoscopic method.

\section{Acknowledgements}

The authors thank L. Bergkvist, Centre of Clinical Research, Central Hospital, Västerås, Sweden, and W.E.G. Thomas, Royal Hallamshire Hospital, Sheffield, UK for assistance with manuscript preparation, and Stefan Sörensen, Mälardalen University, Västerås, Sweden for 
statistical support. The following surgeons also participated in the study: H. Liljeholm and B. Nilsson (Enköpings lasarett), C. Lindstedt and L. Ling (Helsingborgs lasarett), A. Carlstedt, H. Gerdes, L. Spangen and K.-G. Wirehag (Centralsjukhuset Karlstad), M. Bergenfeldt, F. Berndsen, M. Hedberg and U. Pettersson (Universitetssjukhuset, Malmö), M. Johansson, G. Rimbäck, M. Stiernstam and U. Wingren (Mölndals sjukhus), B. Ahlman, U. Jersenius and I. Svedberg (St Görans sjukhus Stockholm), P. Almqvist, G. Isacsson and E. Olsson (Trelleborgs lasarett), D. Arvidsson, B.-Å. Elfberg, R. Sandbu and S. Sjövall-Mjöberg (Akademiska sjukhuset Uppsala), M. Ljungman, J. Raud and S. Wollert (Centrallasarettet Västerås), K. Brunnström, A. Kempas, T. Kjellin, P.O. Park and P. Sassner (Centrallasarettet Växjö), G. Falco de Mats, H. Klockhoff, L.-G. Larsson, P. Mathiessen, I. Nilsson, G. Wickbom and G. Ågren (Universitetssjukhuset Örebro). Financial support was provided by the Stig and Ragna Gorthon Foundation, and Tyco Healthcare, Norden . Tyco Healthcare did not have any involvement in the design and conduct of the study or the data analysis.

\section{References}

1 Amid PK, Shulman AG, Lichtenstein IL. Open 'tension-free' repair of inguinal hernias: the Lichtenstein technique. Eur 7 Surg 1996; 162: 447-453.

2 Davies N, Thomas M, McIlroy B, Kingsnorth AN. Early results with the Lichtenstein tension-free hernia repair. $\mathrm{Br} \mathcal{F}$ Surg 1994; 81: 1478-1479.

3 Shulman AG, Amid PK, Lichtenstein IL. A survey of non-expert surgeons using the open tension-free mesh patch repair for primary inguinal hernias. Int Surg 1995; 80: 35-36.

4 Nilsson E, Haapaniemi S, Gruber G, Sandblom G. Methods of repair and risk for reoperation in Swedish hernia surgery from 1992 to 1996. Br F Surg 1998; 85: 1686-1691.

5 Ramshaw BJ, Tucker JG, Conner T, Mason EM, Duncan TD, Lucas GW. A comparison of the approaches to laparoscopic herniorrhaphy. Surg Endosc 1996; 10: 29-32.

6 Vanclooster P, Meersman AL, de Gheldere CA, Van de Ven CK. The totally extraperitoneal laparoscopic hernia repair. Preliminary results. Surg Endosc 1996; 10: 332-335.

7 Felix EL, Michas CA, Gonzalez MH Jr. Laparoscopic hernioplasty. TAPP vs TEP. Surg Endosc 1995; 9: 984-989.

8 Berndsen F, Arvidsson D, Enander LK, Leijonmarck CE, Wingren U, Rudberg C et al. Postoperative convalescence after inguinal hernia surgery: prospective randomized multicenter study of laparoscopic versus Shouldice inguinal hernia repair in 1042 patients. Hernia 2002; 6: 56-61.

9 Nordin P, Haapaniemi S, van der Linden W, Nilsson E. Choice of anesthesia and risk of reoperation for recurrence in groin hernia repair. Ann Surg 2004; 240: 187-192.
10 Liem MS, van der Graaf Y, van Steensel CJ, Boelhouwer RU, Clevers G-J, Meijer WS et al. Comparison of conventional anterior surgery and laparoscopic surgery for inguinal-hernia repair. N Engl f Med 1997; 336: 1541-1547.

11 Neumayer L, Jonasson O, Fitzgibbons R, Henderson W, Gibbs J, Carrico CJ et al. Tension-free inguinal hernia repair: the design of a trial to compare open and laparoscopic surgical techniques. 7 Am Coll Surg 2003; 196: 743-752.

12 Hair A, Duffy K, McLean J, Taylor S, Smith H, Walker A et al. Groin hernia repair in Scotland. Br 7 Surg 2000; 87: $1722-1726$.

13 Nordin P, Haapaniemi S, Kald A, Nilsson E. Influence of suture material and surgical technique on risk of reoperation after non-mesh open hernia repair. Br 7 Surg 2003; 90: 1004-1008.

14 Danielsson P, Isacson S, Hansen MV. Randomised study of Lichtenstein compared with Shouldice inguinal hernia repair by surgeons in training. Eur 7 Surg 1999; 165: 49-53.

15 Schrenk P, Woisetschlager R, Rieger R, Wayand W. Prospective randomized trial comparing postoperative pain and return to physical activity after transabdominal preperitoneal, total preperitoneal or Shouldice technique for inguinal hernia repair. Br 7 Surg 1996; 83: 1563-1566.

16 Lau H, Patil NG, Yuen WK, Lee F. Management of peritoneal tear during endoscopic extraperitoneal inguinal hernioplasty. Surg Endosc 2002; 16: 1474-1477.

17 Montgomery A. TEP: for super specialist, not for the general surgeon? In Meshes: Benefits and Risks, Schumpelick V, Nyhus LM (eds). Springer: Berlin, 2004; 379-387.

18 Liem MS, van Steensel CJ, Boelhouwer RU, Weidema WF, Clevers GJ, Meijer WS et al. The learning curve for totally extraperitoneal laparoscopic inguinal hernia repair. $A m \mathcal{F}$ Surg 1996; 171: 281-285.

19 Tamme C, Scheidbach H, Hampe C, Schneider C, Kockerling F. Totally extraperitoneal endoscopic inguinal hernia repair (TEP). Surg Endosc 2003; 17: 190-195.

20 Andersson B, Hallen M, Leveau P, Bergenfelz A, Westerdahl J. Laparoscopic extraperitoneal inguinal hernia repair versus open mesh repair: a prospective randomized controlled trial. Surgery 2003; 133: 464-472.

21 Eugene JR, Gashti M, Curras EB, Schwartz K, Joseph E. Regarding 'Small bowel obstruction as a complication of laparoscopic extraperitoneal inguinal hernia repair'. 7 Laparoendosc Adv Surg Tech A 1998; 8: 61-62.

22 EU Hernia Trialists Collaboration. Laparoscopic compared with open methods of groin hernia repair: systematic review of randomized controlled trials. Br F Surg 2000; 87: 860-867.

23 Voyles CR, Hamilton BJ, Johnson WD, Kano N. Meta-analysis of laparoscopic inguinal hernia trials favors open hernia repair with preperitoneal mesh prosthesis. Am $\mathcal{f}$ Surg 2002; 184: 6-10.

24 Liem MS, van der Graaf Y, Zwart RC, Geurts I, van Vroonhoven TJ. A randomized comparison of physical performance following laparoscopic and open inguinal hernia repair. The Coala Trial Group. Br 7 Surg 1997; 84: 64-67. 
25 Courtney CA, Duffy K, Serpell MG, O’Dwyer PJ. Outcome of patients with severe chronic pain following repair of groin hernia. Br 7 Surg 2002; 89: 1310-1314.

26 Neumayer L, Giobbie-Hurder A, Jonasson O, Fitzgibbons R $\mathrm{Jr}$, Dunlop D, Gibbs J et al. Open mesh versus laparoscopic mesh repair of inguinal hernia. $N$ Engl 7 Med 2004; 350:

$1819-1827$.

27 Nyhus LM. The preperitoneal approach and iliopubic tract repair of inguinal hernias. In Hernia, 4 th edn. Nyhus LM, Condon RE (eds). JB Lippincott: Philadelphia, 1995.

If you wish to comment on this, or any other article published in the BJS, please visit the on-line correspondence section of the website (www.bjs.co.uk). Electronic communications will be reviewed by the Correspondence Editor and a selection will appear in the correspondence section of the Journal. Time taken to produce a thoughtful and well written letter will improve the chances of publication in the Journal. 